\title{
Estudio Microbiológico e Histopatológico en Peces Tetra Neón (Paracheirodon innesi) de la Amazonía Peruana
}

\author{
Microbiological and Histopathological Study in Fishes Neon Tetra \\ (Paracheirodon inNesi) from the Peruvian Amazon
}

Shirley Palacios H. ${ }^{1,3}$, Nieves Sandoval C. ${ }^{1}$, Chen Bueno M. ${ }^{1}$, Alberto Manchego S. ${ }^{2}$

\section{Resumen}

\begin{abstract}
El objetivo del presente estudio fue determinar la presencia de agentes infecciosos mediante estudios microbiológicos e histopatológicos en tetra neón (Paracheirodon innesi), pez amazónico ornamental. Se colectaron 168 peces, al azar, del acuario de un acopiador minorista de peces ornamentales de Iquitos, Perú. En la necropsia de 84 peces se tomaron muestras de riñón y bazo para el aislamiento de bacterias en agar tripticasa de soya (TSA), Citophaga (AO) y Middlebrook 7H9, haciendo la identificación mediante coloración Gram y análisis bioquímico. El estudio histopatológico se hizo con los 84 peces restantes. Se aislaron bacterias de los géneros Flavobacterium, Staphylococcus, Carnobacterium, Pseudomonas, Enterococcus, Bacillus y de la familia Enterobacteriaceae. En branquias se observó hiperplasia lamelar, fusión de lamelas, así como presencia de esporas de Mixosporidia en los ápices de las lamelas; en intestino se encontró hiperplasia del epitelio y presencia de esporas de Microsporidium en enterocitos; en hígado se encontró degeneración hidrópica, grasa y presencia de un granuloma parasitario; en riñones se encontró edema peritubular y degeneración hidrópica tubular; y en músculo esquelético se encontró necrosis, granulomas y presencia de quistes de Mixosporidium y esporas de Microsporidium, Pleistophora y Heterosporis.
\end{abstract}

Palabras clave: tetra neón, estudio microbiológico, estudio histopatológico, Microsporidium

${ }^{1}$ Laboratorio de Histología, Embriología y Patología Veterinaria, ${ }^{2}$ Laboratorio de Microbiología y Parasitología Veterinaria, Facultad de Medicina Veterinaria, Universidad Nacional Mayor de San Marcos, Lima, Perú

${ }^{3}$ E-mail: smariepalacioshuayta@gmail.com

Recibido: 21 de agosto de 2014

Aceptado para publicación: 20 de marzo de 2015 
The aim of this study was to determine the presence of infectious agents by microbiological and histopathological studies in the neon tetra (Paracheirodon innesi), an Amazonian ornamental fish. A total of 168 fish were randomly collected from the aquarium of an ornamental fish retail collector in Iquitos, Peru. For the microbiological study, kidney and spleen samples were collected during the necropsy of 84 specimens, and bacteria were isolated in trypticase soy agar (TSA), Citophaga (AO) and Middlebrook 7H9, while identification was done through Gram staining and biochemical analysis. The histopathological study was conducted in the remaining 84 fish. Bacteria isolated were of genera Flavobacterium, Staphylococcus, Carnobacterium, Pseudomonas, Enterococcus, Bacillus and of the Enterobacteriaceae family. In gills was observed laminar hyperplasia, fusion of lamellae and Mixosporidia spores at the tips of the lamellae; in the intestine was observed epithelial hyperplasia of the bowel and spores of Microsporidium in the intestinal villi; in the liver was found hydropic and fatty degeneration and a parasitic granuloma; in kidneys was found peritubular edema and hydropic degeneration; and in the muscular skeletal was found necrosis, presence of Mixosporidium cysts, granulomas, and spores of Microsporidium, Pleistophora and Heterosporis.

Key words: neon tetra, microbiological study, histopathological study, Microsporidium

\section{INTRODUCCIÓN}

La actividad pesquera ornamental en una importante fuente de ingreso de divisas para el país y de sustento para miles de familias dedicadas a este rubro del quehacer económico regional. En el Perú, la actividad de comercialización del recurso peces ornamentales se inicia a partir de la década del cincuenta, desde la ciudad de Iquitos hacia el exterior; en ese entonces, principalmente con la ciudad de Miami, EEUU (Rojas, 1972). El nivel de extracción de peces ornamentales en las diferentes cuencas del país ha ido variando a través del tiempo. La cuenca del río Napo fue la más importante en la década de los 70, la cuenca del Nanay en la década de los 80 y la cuenca del Ucayali en la década de los 90 hasta la actualidad (Ruíz et al., 2003).

Diversos eventos relacionados al medio ambiente acuático o de manejo de los peces pueden conducir a alteraciones en la salud de los peces; especialmente por efecto de enfermedades de tipo infecciosas y no infecciosas (Centeno et al., 2004).
Dentro del grupo de enfermedades infecciosas que afectan la salud de los peces ornamentales amazónicos, figuran las enfermedades bacterianas, virales, fúngicas y parasitarias que a menudo ocasionan lesiones externas e internas, muchas de las cuales pueden ocasionar la muerte y ser una fuente de dispersión de la enfermedad en el agua (Centeno et al., 2004). Las bacterias relacionadas con enfermedad pueden provenir de la flora bacteriana de los peces, así como por bacterias introducidas por una mala práctica en el manejo; lo cual sumado a alguna condición estresante en los peces, los convierten en individuos susceptibles de padecer alguna infección. Algunas bacterias, a la vez, pueden tener cierta capacidad zoonótica, ocasionando problemas en la salud pública (Roberts, 2001).

Los peces tetra neón pertenecen al Orden Characiformes, familia Characidae, siendo una especie muy apreciada en la acuariofilia por su carácter pacífico, su llamativo color y sus desplazamientos en cardumen que dan vida al acuario. Presentan una franja azul fosforescente que recorre su cuerpo desde 
el morro hasta la aleta adiposa. La parte inferior es de un rojo luminoso que se extiende desde la parte anterior hasta la mitad del cuerpo. Son peces pequeños, de 2 a $4 \mathrm{~cm}$ de longitud, adaptados a temperaturas entre 21 a $28{ }^{\circ} \mathrm{C}$. Pueden vivir entre 6 y 7 años. Son omnívoros, con especial predilección por el alimento vivo, como artemia salina, tubifex, larvas de mosquito, daphnias y pequeños gusanos, así como alimento liofilizado (Herbert y Dauner, 2002). Se les encuentra en el curso principal del río Amazonas y sus tributarios en Brasil, Colombia y Perú (Petracini, 2013).

El presente trabajo tuvo como objetivo realizar un estudio histopatológico y microbiológico en peces tetra neón (Paracheirodon innesi) de la amazonia peruana.

\section{Materiales y Métodos}

\section{Lugar de Estudio y Material Biológico}

Se trabajó con muestras de peces tetra neón (Paracheirodon innesi), adquiridos de un acopiador minorista de peces ornamentales amazónicos de la ciudad de Iquitos, Loreto, Perú. Este acopiador adquiere peces capturados en los ríos por pescadores artesanales y abastece los comercios locales de la ciudad de Lima. El estudio microbiológico e histopatológico se desarrolló en la sección de ictiopatología del Laboratorio de Histología, Embriología y Patología Veterinaria de la Facultad de Medicina Veterinaria (FMV), Universidad Nacional Mayor de San Marcos (UNMSM), Lima. La calidad del agua de los acuarios donde fueron adquiridos los peces no se pudo determinar.

Se seleccionaron 168 peces con un tamaño promedio de $2.07 \pm 0.02 \mathrm{~cm}$ de longitud total. Los peces eran adultos pues las gónadas estaban desarrolladas. La toma de muestras se vio dificultada por el tamaño pequeño de los peces y de sus órganos (bazo: $0.2 \mathrm{~mm}$ de diámetro; riñón: $0.3 \mathrm{~mm}$ de ancho y $1 \mathrm{~cm}$ de largo), de allí que se optó por utili- zar la mitad de los peces para el estudio microbiológico y la otra mitad para el estudio histopatológico.

\section{Toma de Muestras}

Los peces fueron trasladados al laboratorio de la FMV-UNMSM en tres grupos (60, 60 y 48 individuos) en bolsas de polietileno, conteniendo $1 / 4$ de agua y $3 / 4$ de oxígeno. Al arribo al laboratorio, los peces fueron colocados en tres acuarios por $72 \mathrm{~h}$ hasta el inicio del estudio. Los acuarios fueron de igual tamaño, con un volumen de $25 \mathrm{~L}$ de agua y con una temperatura del agua de $26^{\circ} \mathrm{C}$, apropiada para este tipo de pez amazónico. Durante este tiempo, se tuvo una observación continua de los peces para detectar posibles alteraciones de la conducta. Así mismo, se controló la calidad de agua (temperatura, $\mathrm{pH}$, retiro del sedimento).

Los peces recibieron alimento a las $24 \mathrm{~h}$ después de su arribo, consistente en micropellets (Kubitza, 2009; Auburn University, 2014).

Los peces fueron sacrificados a las 72 horas de la llegada al laboratorio. Previamente, los peces se colocaron en un recipiente con agua conteniendo benzocaína $1 \mathrm{~g} / 20 \mathrm{~L}$ (Ross y Ross, 2008) por espacio de 10 a 15 segundos, siguiendo las recomendaciones del Comité de Ética y Bienestar Animal de la FMV-UNMSM. Se realizó el examen externo para identificar lesiones o parásitos externos y luego se desinfectó la superficie del pez con alcohol al 70\%. El sacrificio se hizo mediante la técnica de corte medular con hoja de bisturí, entre el cerebro y la médula espinal (Roberts y Shepherd, 1980; Rosenthal, 2007) y se procedió a la necropsia según las técnicas de rutina (Reimschuessel et al., 1988).

\section{Estudio Microbiológico}

Con ayuda de una lupa, se hizo una punción en la superficie del riñón y del bazo, y se utilizó el ansa estéril de punta para el aislamiento de bacterias. Las muestras fueron 
sembradas por triplicado en medio Tripticasa Soya Agar (TSA), Agar Cytophaga y Middlebrook 7H9. La incubación se hizo a $28{ }^{\circ} \mathrm{C}$ por $24 \mathrm{~h}$ (TSA), $96 \mathrm{~h}$ (Cytophaga) y por 2 a 4 semanas (Middlebrook 7H9). Los aislados obtenidos fueron sembrados en agar Luria y conservados en refrigeración $\left(8^{\circ} \mathrm{C}\right)$ hasta completar el proceso de siembra de las muestras de los 84 peces.

Los aislados fueron reactivados a través del cultivo en caldo de tripticasa de soya (TSB) a $28^{\circ} \mathrm{C}$ por $24 \mathrm{~h}$ y en caldo Cytophaga a $28{ }^{\circ} \mathrm{C}$ por $96 \mathrm{~h}$, y resembrados en agar TSA y Cytophaga a $28^{\circ} \mathrm{C}$ por $24 \mathrm{~h}$ y $96 \mathrm{~h}$, respectivamente.

La caracterización cultural de cada colonia se hizo mediante la coloración Gram y pruebas bioquímicas (oxidasa, catalasa, Medio LIA, Agar Simmons Citrato, Caldo de nitritos, Medio TSI, Medio Rojo de Metilo, Medio base de Hugh y Leifsony Medio SIM). Para la detección de indol se agregó el reactivo de Kovacs. Se hizo una lectura inicial a las $24 \mathrm{~h}$ y una final a las $48 \mathrm{~h}$. La interpretación de los resultados de cada colonia aislada se hizo de acuerdo a lo descrito por Buller (2004).

\section{Estudio Histopatológico}

Debido al pequeño tamaño de los peces, se les colocó en casetes histológicos seccionando la aleta caudal (cola) y se les fijó en formol tamponado al 10\%. Se les procesó mediante el protocolo histológico convencional para tejidos fijados, utilizando alcoholes en concentraciones ascendentes, xilol para el aclaramiento de los tejidos e infiltración en parafina hasta la obtención de bloques de tejidos parafinados.

Se hicieron cortes de $5 \mu \mathrm{m}$. Las láminas fueron coloreadas con hematoxilina y eosina (H\&E) y observadas con un microscopio óptico de luz con objetivos de 10, 40 y $100 X$. Se realizó un corte histológico sagital de cada muestra parafinada que permitiera observar los órganos internos.
Los peces fueron colocados en casettes histológicos y fijados en formol tamponado al $10 \%$. Las láminas fueron coloreadas con hematoxilina y eosina (H\&E) y observadas con un microscopio óptico de luz con objetivos de 10,40 y 100X. Se realizaron ensayos previos para determinar el corte histológico sagital adecuado que permitiera observar los órganos internos debido a su reducido tamaño.

\section{Análisis de Datos}

Las lesiones histopatológicas fueron clasificadas para cada órgano en trastornos inflamatorios, circulatorios, del crecimiento, degenerativos y parasitarios (Reimschuessel et al., 1992). Las lesiones fueron clasificadas de acuerdo al grado de afección por su extensión, según se indica en el Cuadro 1, y para el caso de hígado, la degeneración grasa se categorizó según lo indicado en el Cuadro 2 .

Se hizo un análisis de frecuencia, indicando el porcentaje de cada variable con respecto al total de población analizada para cada análisis. Asimismo, los resultados microscópicos de las lesiones se presentan según el grado de afección en una escala de 1 a 4 .

\section{Resultados}

A partir de las muestras de riñón y bazo se obtuvieron 39 aislados que crecieron en los agares TSA y Cytophaga. No se obtuvieron aislados de Mycobacterium sp en el agar Middlebrook 7H9.

Se identificaron seis géneros bacterianos: Flavobacterium $(8 / 39 ; 20.6 \%)$, Staphylococcus $(7 / 39 ; 17.9 \%)$, Carnobacterium (7/39; 17.9\%), Pseudomonas (6/39; $15.4 \%)$, Enterococcus $(4 / 39 ; 10.3 \%)$ y Bacillus (2/39; 5.1\%), así como bacterias de la familia Enterobacteriaceae $(5 / 39 ; 12.8 \%)$.

Dentro de las alteraciones histológicas en las branquias, se observó la hiperplasia del epitelio de revestimiento de las lamelas y la 
Cuadro 1. Clasificación de la lesiones histopatológicas según el grado de afección por su extensión

\begin{tabular}{cl}
\hline Grado & Extensión de la lesión \\
\hline I & Escasa presencia de lesión (hasta $25 \%$ de toda la muestra) \\
II & Leve presencia de lesión (entre más de $25 \%$ hasta $50 \%$ de toda la muestra) \\
III & Moderada presencia de lesión (entre más de $50 \%$ hasta $75 \%$ de toda la muestra) \\
IV & Severa presencia de lesión (más de $75 \%$ de toda la muestra) \\
\hline
\end{tabular}

Fuente: Reimschuessel et al. (1992)

Cuadro 2. Clasificación de la degeneración grasa en el hígado de acuerdo a la severidad y extensión de la lesión

\begin{tabular}{cll}
\hline Grado & Severidad & Extensión \\
\hline I & $\begin{array}{l}\text { Escasa presencia de microvacuolas } \\
\text { intracitoplasmáticas }\end{array}$ & $\begin{array}{l}\text { Multifocal (hasta 25\% de toda la } \\
\text { muestra) }\end{array}$ \\
II & $\begin{array}{l}\text { Leve presencia de micro y/o } \\
\text { macrovacuolas intracitoplasmáticas }\end{array}$ & $\begin{array}{l}\text { Multifocal (entre más de 25\% hasta } \\
50 \% \text { de toda la muestra) }\end{array}$ \\
III & $\begin{array}{l}\text { Moderada presencia de macro y } \\
\text { microvacuolas intracitoplasmáticas }\end{array}$ & $\begin{array}{l}\text { Difuso (entre más de 50\% hasta 75\% } \\
\text { de toda la muestra) }\end{array}$ \\
IV & $\begin{array}{l}\text { Severa presencia de macrovacuolas } \\
\text { intracitoplasmáticas. }\end{array}$ & $\begin{array}{l}\text { Difuso (Más de 75\% de toda la } \\
\text { mue stra) }\end{array}$ \\
\hline
\end{tabular}

Fuente: Reimschuessel et al. (1992), modificado por Rosenthal (2007)

Cuadro 3. Frecuencia de alteraciones histológicas de las branquias según tipo de trastorno y su grado de afección en peces tetra neón (Paracheirodon innesi), procedentes de Iquitos, Perú $(\mathrm{n}=84)$

\begin{tabular}{|c|c|c|c|c|c|c|c|}
\hline \multirow{2}{*}{$\begin{array}{l}\text { Tipo de trastorno / } \\
\text { Lesiones }\end{array}$} & \multicolumn{5}{|c|}{ Grado de afección } & \multicolumn{2}{|c|}{$\begin{array}{l}\text { Total de } \\
\text { afectados }\end{array}$} \\
\hline & No hay & $\begin{array}{l}\text { Escaso } \\
\text { (I) }\end{array}$ & $\begin{array}{l}\text { Leve } \\
\text { (II) }\end{array}$ & $\begin{array}{l}\text { Moderado } \\
\text { (III) }\end{array}$ & $\begin{array}{c}\text { Severo } \\
\text { (IV) }\end{array}$ & $\mathrm{n}$ & $\%$ \\
\hline \multicolumn{8}{|l|}{ Del crecimiento } \\
\hline $\begin{array}{l}\text { Hiperplasia del } \\
\text { epitelio lamelar }\end{array}$ & 0 & 0 & 48 & 36 & 0 & 84 & 100 \\
\hline Fusión lamelas & 0 & 0 & 18 & 65 & 1 & 84 & 100 \\
\hline \multicolumn{8}{|l|}{ Parasitarios } \\
\hline $\begin{array}{l}\text { Esporas de } \\
\text { Mixosporidios sp }\end{array}$ & 0 & 0 & 39 & 45 & 0 & 84 & 100 \\
\hline
\end{tabular}




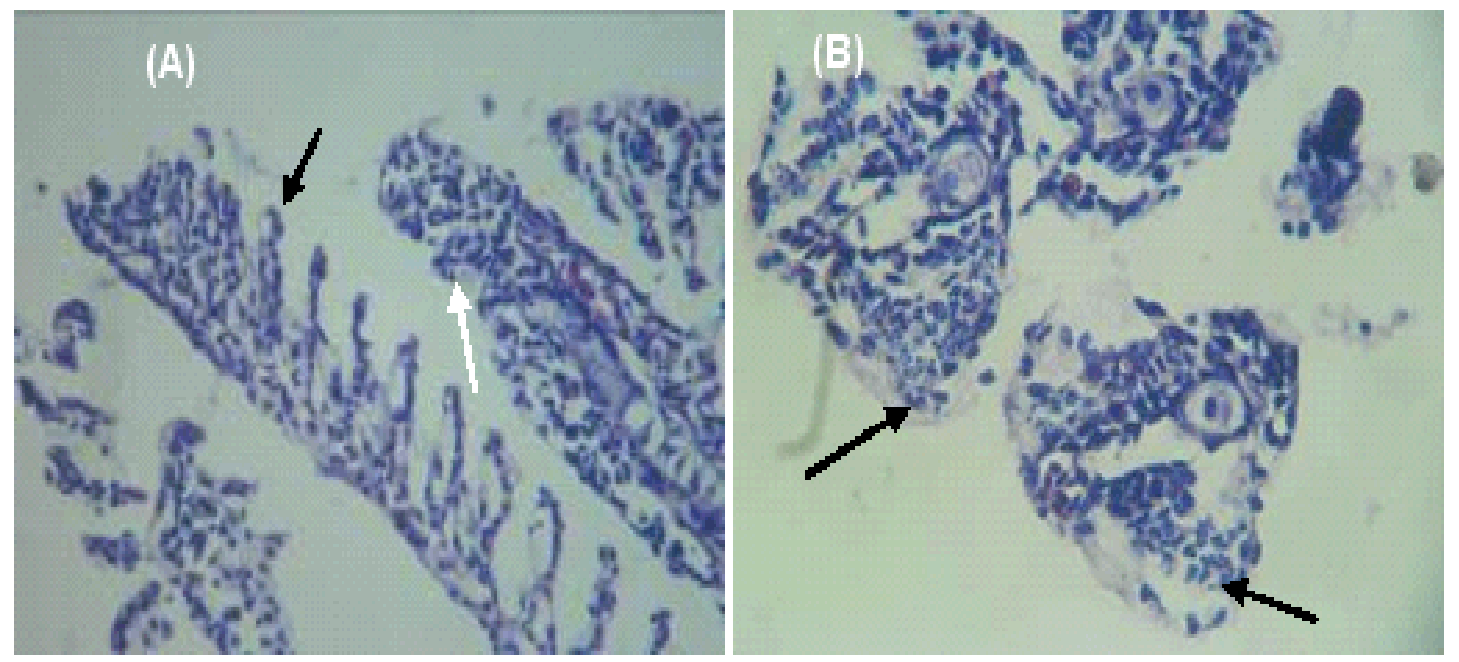

Figura 1. Cortes histológicos de las branquias de tetra neón (Paracheirodon innesi). A. Hiperplasia epitelial (flecha negra) y fusión de lamelas (flecha blanca). H\&E. 400X. B. En el ápice de las lamelas (flechas), se observan esporas de Mixosporidium sp. H\&E. 1000X
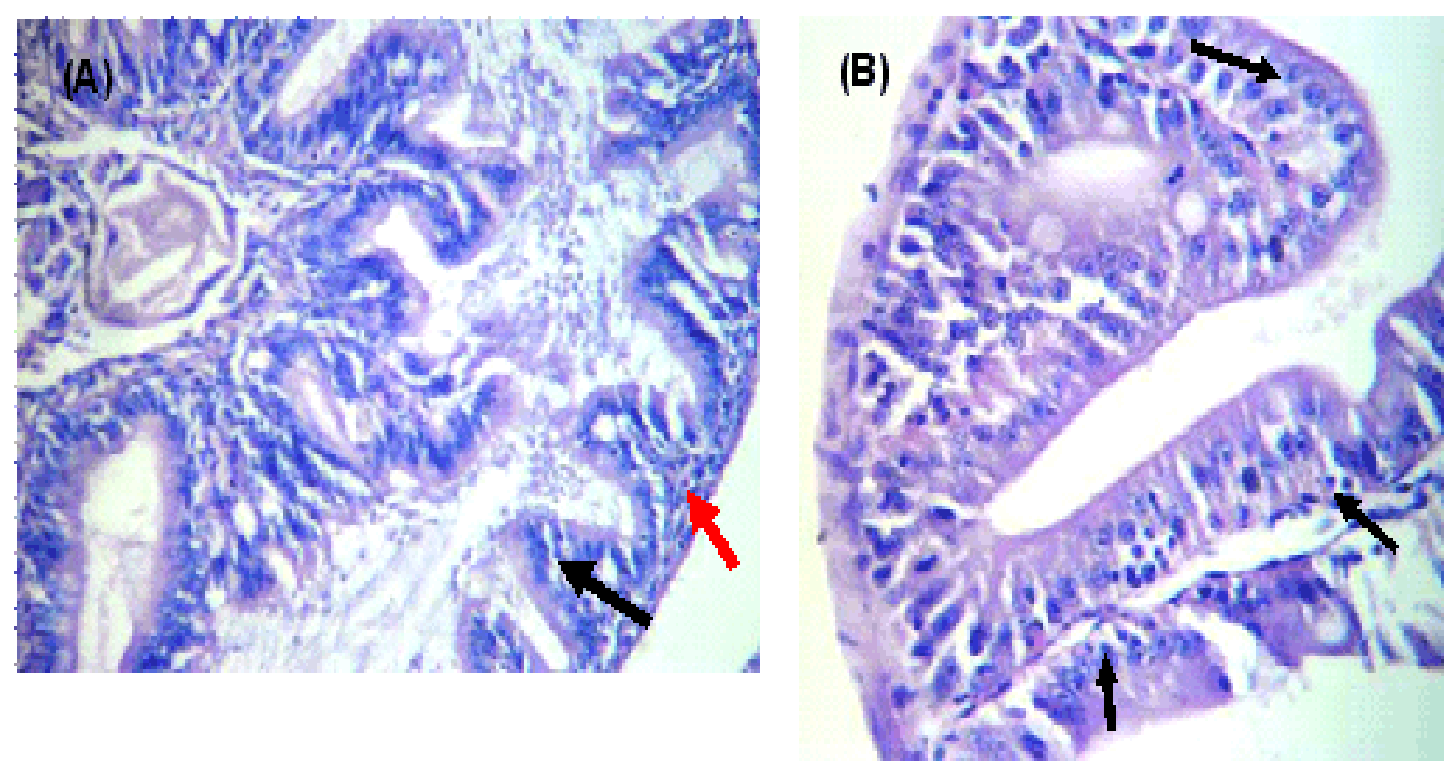

Figura 2. Cortes histológicos del intestino de tetra neón (Paracheirodon innesi). A. Hiperplasia del epitelio de las vellosidade (flechas). H\&E. 1000X. B. Se observa presencia de esporas de Microsporidium sp en las vellosidades intestinales (flechas). H\&E. 1000X

fusión de lamelas en todas las muestras (Cuadro 3, Fig. 1A), siendo estas de manera leve a moderada. Además, se encontraron esporas de mixosporidios, predominantemente en los ápices de las lamelas, con esporas individuales, cada una con cuatro cápsulas polares
(Fig. 1B). No obstante la presencia de estas lesiones, los peces no presentaron alteraciones externas en las branquias ni signos clínicos aparentes de hipoxia (boqueo); posiblemente debido a la lenidad de las lesiones. 
Cuadro 4. Frecuencia de alteraciones histológicas del intestino según tipo de trastorno y su grado de afección en tetra neón (Paracheirodon innesi), procedentes de Iquitos, Perú $(n=84)$

\begin{tabular}{lccccccc}
\hline & \multicolumn{3}{c}{ Grado de afección } & \multicolumn{3}{c}{$\begin{array}{c}\text { Total de } \\
\text { afectados }\end{array}$} \\
\cline { 2 - 8 } \begin{tabular}{l} 
Tipo de trastorno / \\
\cline { 2 - 8 }
\end{tabular} & No hay & $\begin{array}{c}\text { Escaso } \\
\text { (I) }\end{array}$ & $\begin{array}{c}\text { Leve } \\
\text { (II) }\end{array}$ & $\begin{array}{c}\text { Moderado } \\
\text { (III) }\end{array}$ & $\begin{array}{c}\text { Severo } \\
\text { (IV) }\end{array}$ & n & $\%$ \\
\hline $\begin{array}{l}\text { Del crecimiento } \\
\quad \text { Hiperplasia del } \\
\text { epitelio }\end{array}$ & 0 & 0 & 74 & 10 & 0 & 84 & 100 \\
$\begin{array}{c}\text { Parasitarios } \\
\quad \text { Esporas de } \\
\text { Microsporidios }\end{array}$ & 0 & 3 & 47 & 34 & 0 & 84 & 100 \\
\hline
\end{tabular}

Cuadro 5. Frecuencia de alteraciones histológicas del hígado según tipo de trastorno y su grado de afección en tetra neón (Paracheirodon innesi), procedentes de Iquitos, Perú $(\mathrm{n}=84)$

\begin{tabular}{lccccccc}
\hline & \multicolumn{9}{c}{ Grado de afección } & \multicolumn{3}{c}{$\begin{array}{c}\text { Total de } \\
\text { afectados }\end{array}$} \\
\cline { 2 - 7 } $\begin{array}{l}\text { Tipo de trastorno / } \\
\text { Lesiones }\end{array}$ & No hay & $\begin{array}{c}\text { Escaso } \\
\text { (I) }\end{array}$ & $\begin{array}{c}\text { Leve } \\
\text { (II) }\end{array}$ & $\begin{array}{c}\text { Moderado } \\
\text { (III) }\end{array}$ & $\begin{array}{c}\text { Severo } \\
\text { (IV) }\end{array}$ & $\mathrm{n}$ & $\%$ \\
\hline $\begin{array}{c}\text { Degenerativos } \\
\quad \begin{array}{l}\text { Degeneración } \\
\text { Hidrópica } \\
\text { Degeneración } \\
\text { grasa }\end{array}\end{array}$ & 74 & 7 & 2 & 1 & 0 & 10 & 11.9 \\
$\begin{array}{c}\text { Inflamatorios } \\
\quad \text { Granulomas } \\
\text { parasitarios }\end{array}$ & 53 & 0 & 0 & 1 & 30 & 31 & 36.9 \\
\hline
\end{tabular}

Dentro de las alteraciones histológicas en el intestino, se evidenciaron trastornos de crecimiento caracterizados por una leve a moderada hiperplasia del epitelio y leve a moderada presencia de esporas de Microsporidium $\mathrm{sp}$ en las vellosidades intestinales en todas las muestras (Cuadro 4, Fig. 2).
Los trastornos degenerativos más frecuentes en el hígado fueron la degeneración hidrópica (11.9\%), predominando la forma escasa, y una severa degeneración grasa (36.9\%), (Cuadro 5, Fig. 3). Además, se observó la presencia de un granuloma parasitario en el parénquima hepático de uno de los peces (Fig. 3). 
Cuadro 6. Frecuencia de alteraciones histológicas del riñón según tipo de trastorno y su grado de afección en tetra neón (Paracheirodon innesi), procedente de Iquitos, Perú $(n=84)$

\begin{tabular}{lccccccc}
\hline & \multicolumn{3}{c}{ Grado de afección } & \multicolumn{3}{c}{$\begin{array}{c}\text { Total de } \\
\text { afectados }\end{array}$} \\
\cline { 2 - 7 } \begin{tabular}{l} 
Tipo de trastorno / \\
\cline { 2 - 7 }
\end{tabular} & No hay & $\begin{array}{c}\text { Escaso } \\
\text { (I) }\end{array}$ & $\begin{array}{c}\text { Leve } \\
\text { (II) }\end{array}$ & $\begin{array}{c}\text { Moderado } \\
\text { (III) }\end{array}$ & $\begin{array}{c}\text { Severo } \\
\text { (IV) }\end{array}$ & n & $\%$ \\
\hline $\begin{array}{l}\text { Degenerativa } \\
\begin{array}{l}\text { Edema } \\
\text { peritubular }\end{array}\end{array}$ & 0 & 0 & 71 & 13 & 0 & 84 & 100 \\
$\begin{array}{l}\text { Degeneración } \\
\text { hidrópica }\end{array}$ & 0 & 0 & 78 & 6 & 0 & 84 & 100 \\
\hline
\end{tabular}

Cuadro 7. Frecuencia de alteraciones histológicas del músculo esquelético según tipo de trastorno y su grado de afección en tetra neón (Paracheirodon innesi), procedentes de Iquitos, Perú $(\mathrm{n}=84)$

\begin{tabular}{|c|c|c|c|c|c|c|c|}
\hline \multirow{2}{*}{$\begin{array}{l}\text { Tipo de trastorno / } \\
\text { Lesiones }\end{array}$} & \multicolumn{5}{|c|}{ Grado de afección } & \multicolumn{2}{|c|}{$\begin{array}{l}\text { Total de } \\
\text { afectados }\end{array}$} \\
\hline & No hay & $\begin{array}{l}\text { Esc aso } \\
\text { (I) }\end{array}$ & $\begin{array}{l}\text { Leve } \\
\text { (II) }\end{array}$ & $\begin{array}{l}\text { Moderado } \\
\text { (III) }\end{array}$ & $\begin{array}{l}\text { Severo } \\
\text { (IV) }\end{array}$ & $\mathrm{n}$ & $\%$ \\
\hline \multicolumn{8}{|l|}{ Degenerativa } \\
\hline $\begin{array}{l}\text { Necrosis } \\
\text { muscular }\end{array}$ & 0 & 0 & 54 & 27 & 3 & 84 & 100 \\
\hline \multicolumn{8}{|c|}{ Trastornos inflamatorios } \\
\hline $\begin{array}{l}\text { Granulomas } \\
\text { parasitarios }\end{array}$ & 0 & 2 & 0 & 0 & 0 & 2 & 2.4 \\
\hline $\begin{array}{l}\text { Granulomas } \\
\text { bacterianos }\end{array}$ & 0 & 1 & 0 & 0 & 0 & 1 & 1.2 \\
\hline
\end{tabular}

Los trastornos degenerativos más frecuentes en riñón fueron un leve a moderado edema peritubular y degeneración hidrópica tubular, los cuales se presentaron en todas las muestras (Cuadro 6, Fig. 4).

En el caso del músculo esquelético se observaron trastornos degenerativos, siendo estos de una leve a moderada necrosis muscular en todos los peces (Fig. 5A), así como alteraciones inflamatorias incluyendo granulomas de tipo parasitario (Figs. 5E, 6) y bacterianos (Cuadro 7). Además, se encontró esporas de Microsporidium sp, en un grado de leve a moderado en todos los peces (Fig. 5A), así como un quiste de Mixosporidium $\mathrm{sp}$ con estadios esporogónicos inmaduros (Fig. 5B) en un pez, esporas de Pleistophora sp en un pez (Fig. 5C), y esporas de Heterosporis sp en otro pez (Fig. 5D). 

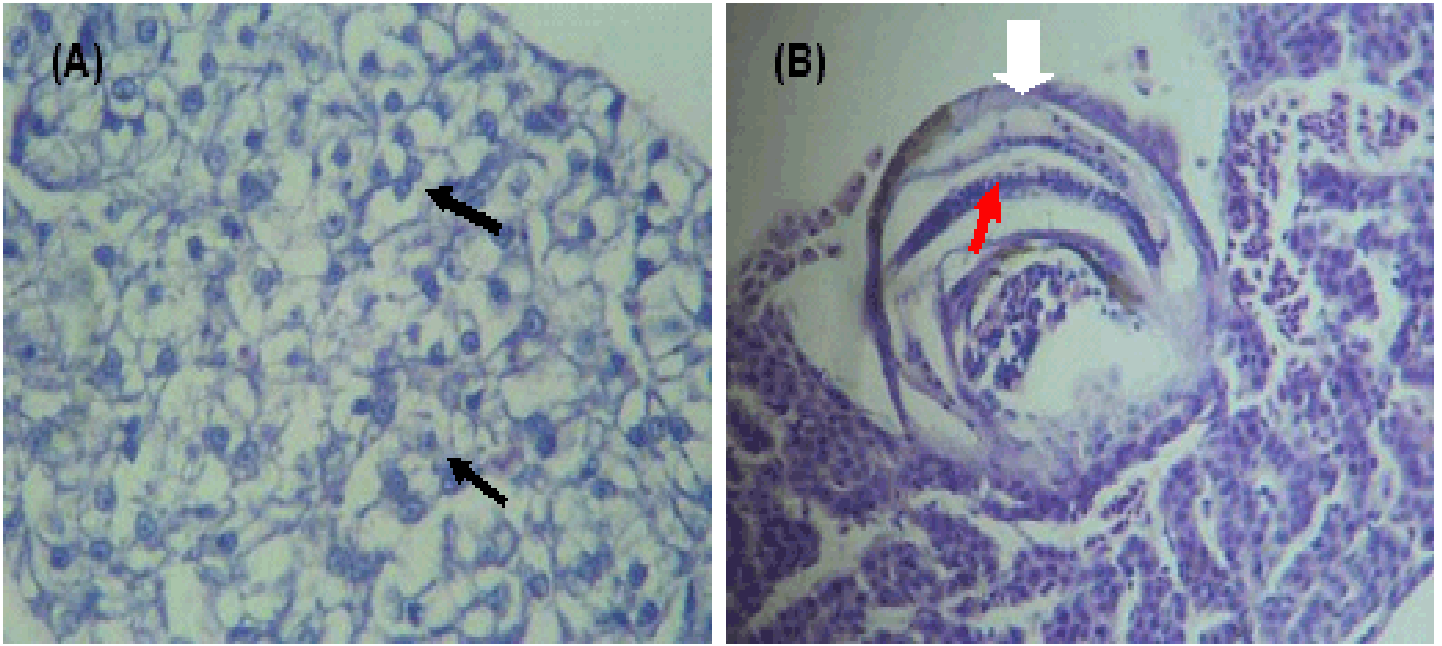

Figura 3. Corte histológico de hígado de tetra neón (Paracheirodon innesi). A. Se observan los hepatocitos hinchados con uni y multivacuolas intracitoplasmáticas desplazando al núcleo a la periferie (flechas). Degeneración grasa Grado 4. H\&E. 400X. B. Granuloma parasitario (flecha blanca). Se observa externamente fibroblastos com melanomacrófagos (flecha negra corta) que rodean al parásito que se encuentra internamente (flecha roja corta). H\&E. 1000X
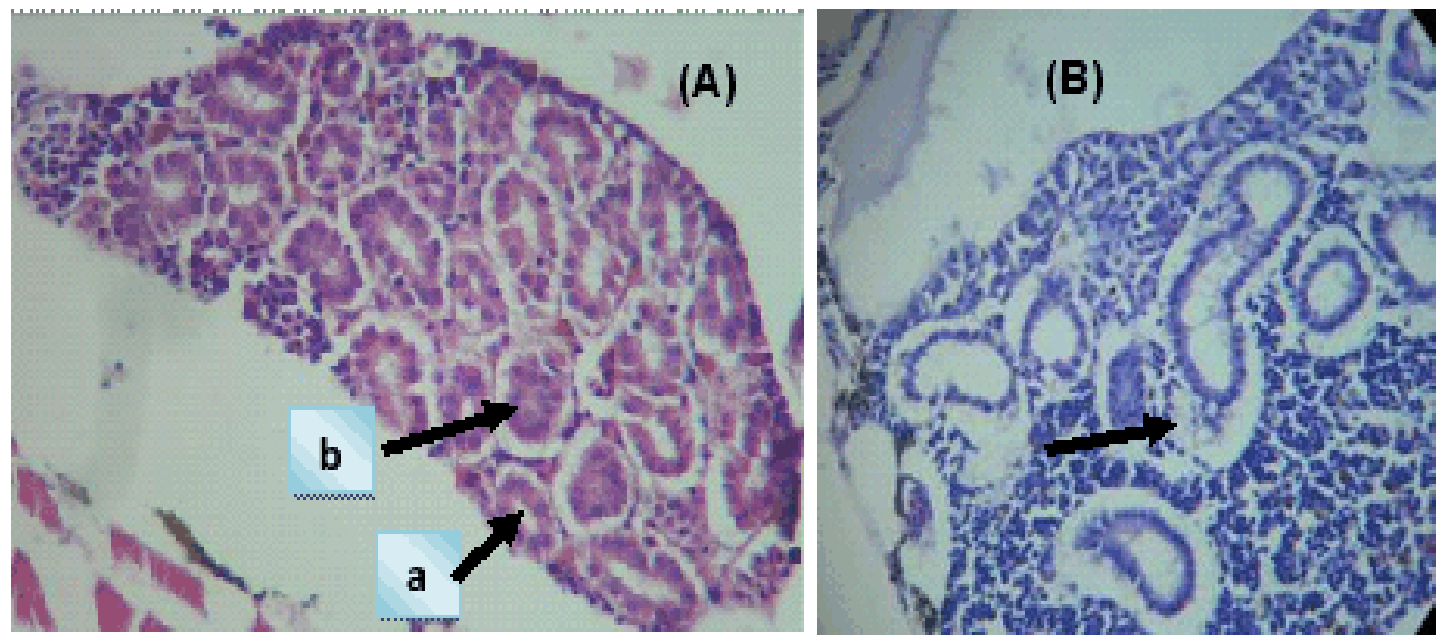

Figura 4. Corte histológico de riñón de tetra neón (Paracheirodon innesi). A. Edema peritubular (flecha a) y degeneración hidrópica (flecha b). H\&E. 1000X. B. Edema peritubular (flecha). H\&E. 1000X

Asimismo, se observaron múltiples granulomas de tamaño diverso, cercanos al hígado, intestino y gónadas (Fig. 7), los cuales son característicos en algunos procesos infecciosos de tipo bacteriano. La leve a moderada presencia de formas parasitarias en el músculo esquelético de algunos peces no les causó signos clínicos aparentes. 

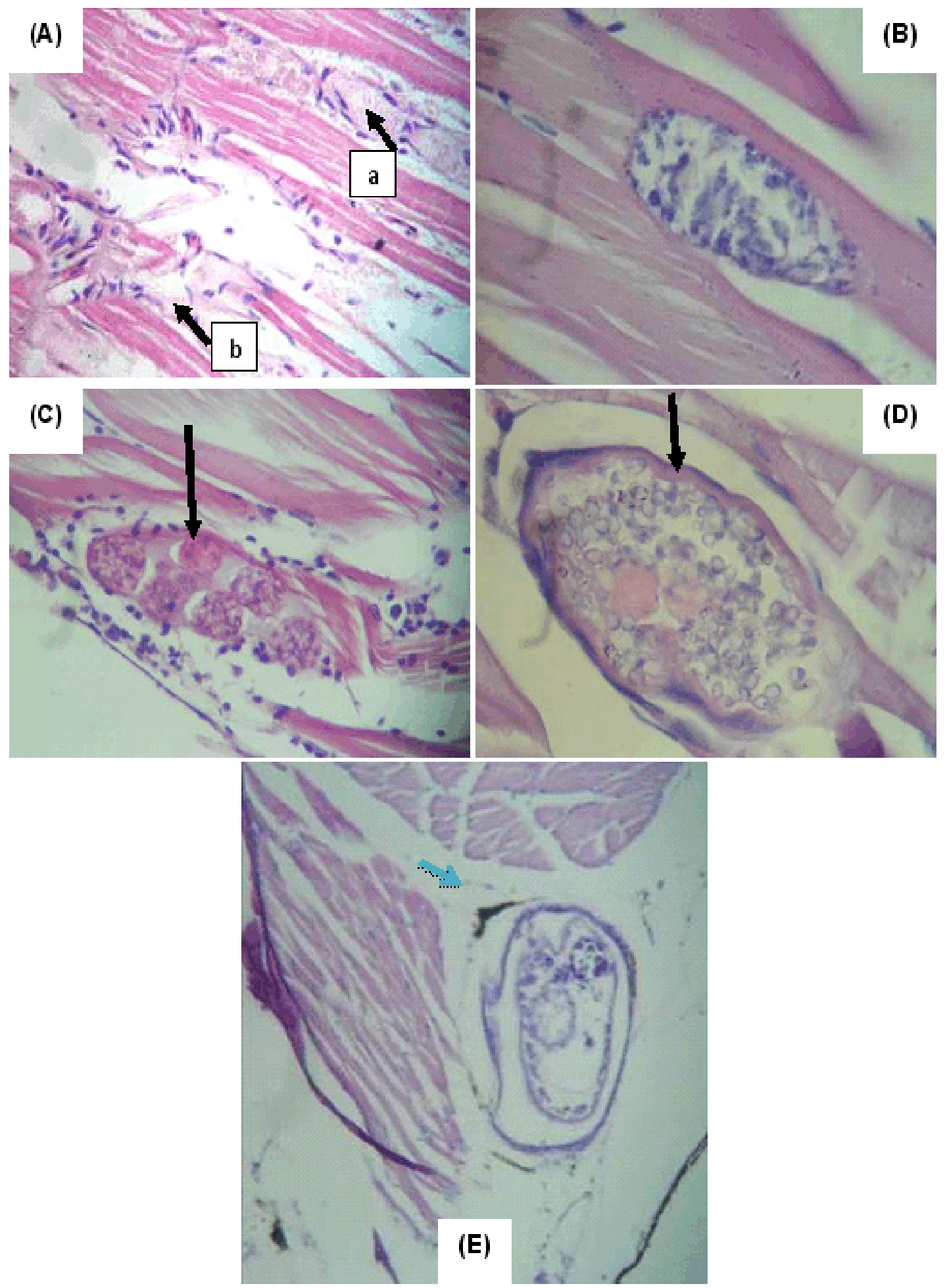

Figura 5. Corte histológico de músculo esquelético de tetra neón (Paracheirodon innesi). A. Necrosis (flecha a) y presencia de esporas de Microsporidium sp (flecha b). H\&E. 400X. B. Quiste de Mixosporidium sp. H\&E. 1000X. C. Esporas de Pleistophora sp (flecha). H\&E. 1000X. D. Heterosporis sp. H\&E. 1000X. E. Granuloma parasitario. Externamente se observa fibroblastos y escasos melanomacrófagos (flecha) rodeando a uma cercaria. H\&E. $1000 X$ 


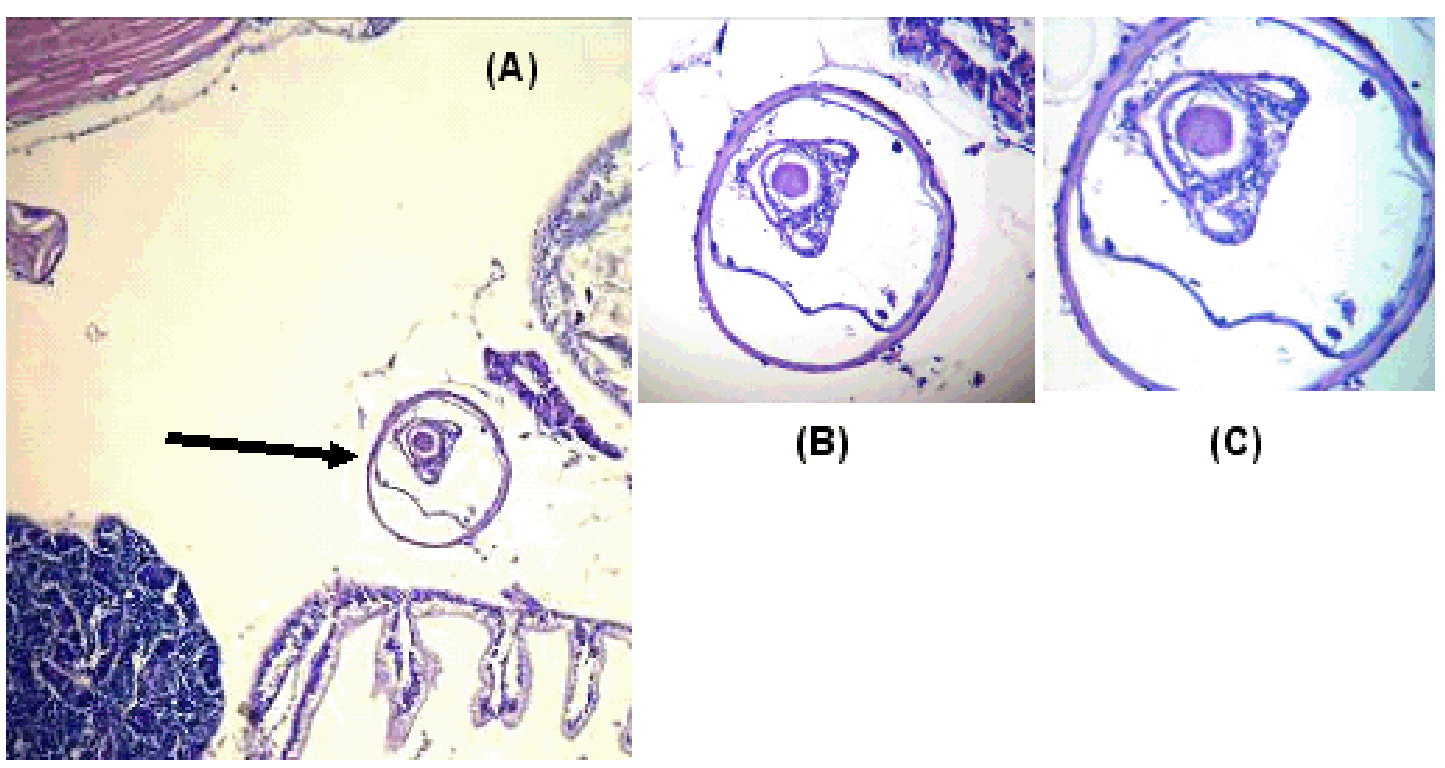

Figura 6. Granuloma parasitario. A. Granuloma señalado con la fecha. 1000X. B. Obsérvese la distribución de fibroblastos que han reemplazado a los macrófagos. 400X. C. La figura previa a mayor aumento. 1000X. H\&E

\section{Discusión}

Estudios relacionados a las alteraciones histopatológicas y al estudio microbiológico en peces ornamentales amazónicos como tetra neón, no han sido descritos hasta el momento en el país. En el presente estudio, las lesiones halladas en las branquias fueron una leve a moderada hiperplasia del epitelio del revestimiento lamelar, así como de fusión lamelar. Noga (2000) afirma que este tipo de lesiones son respuestas comunes ante el daño branquial; asimismo, indica que las lesiones en branquias tienen un alto grado de inespecificidad, y pueden ser originadas por bacterias, parásitos o una pobre calidad del agua.

Las lesiones en branquias en el presente estudio podrían ser explicadas por las presencia de Mixosporidium sp y a la mala calidad del agua, debido a que los peces provienen de la captura en ríos y las fuentes de agua del Amazonas, que contienen generalmente altas cargas de materia orgánica y desechos tóxicos (Verján, 2002). No obstante, los peces muestreados no presentaron alteraciones externas en las branquias ni signos clínicos aparentes de hipoxia, dada la lenidad de las lesiones.

Las lesiones de tipo leve a moderada de hiperplasia del epitelio intestinal pudieron ser debidas a un periodo de ayuno prolongado o por situaciones de estrés por la captura y traslado, lo cual puede generar cambios en la permeabilidad intestinal (Farhadi et al., 2003; Lambert, 2003). Así mismo, la hiperplasia de los enterocitos y células mucosas pueden ser consecuencia de la presencia de parásitos en la mucosa (Jubb et al., 2007). En este estudio, los peces pasaron por un ayuno de casi 72 horas desde su traslado desde Iquitos hasta el inicio de alimentación en el laboratorio en Lima, lo cual favorecería a la presentación de este cambio adaptativo; sin embargo, la causa más probable está relacionada a la presencia de Microsporidium sp, enquistados en los enterocitos, que indujo, además, el acortamiento y pérdida de las vellosidades. 


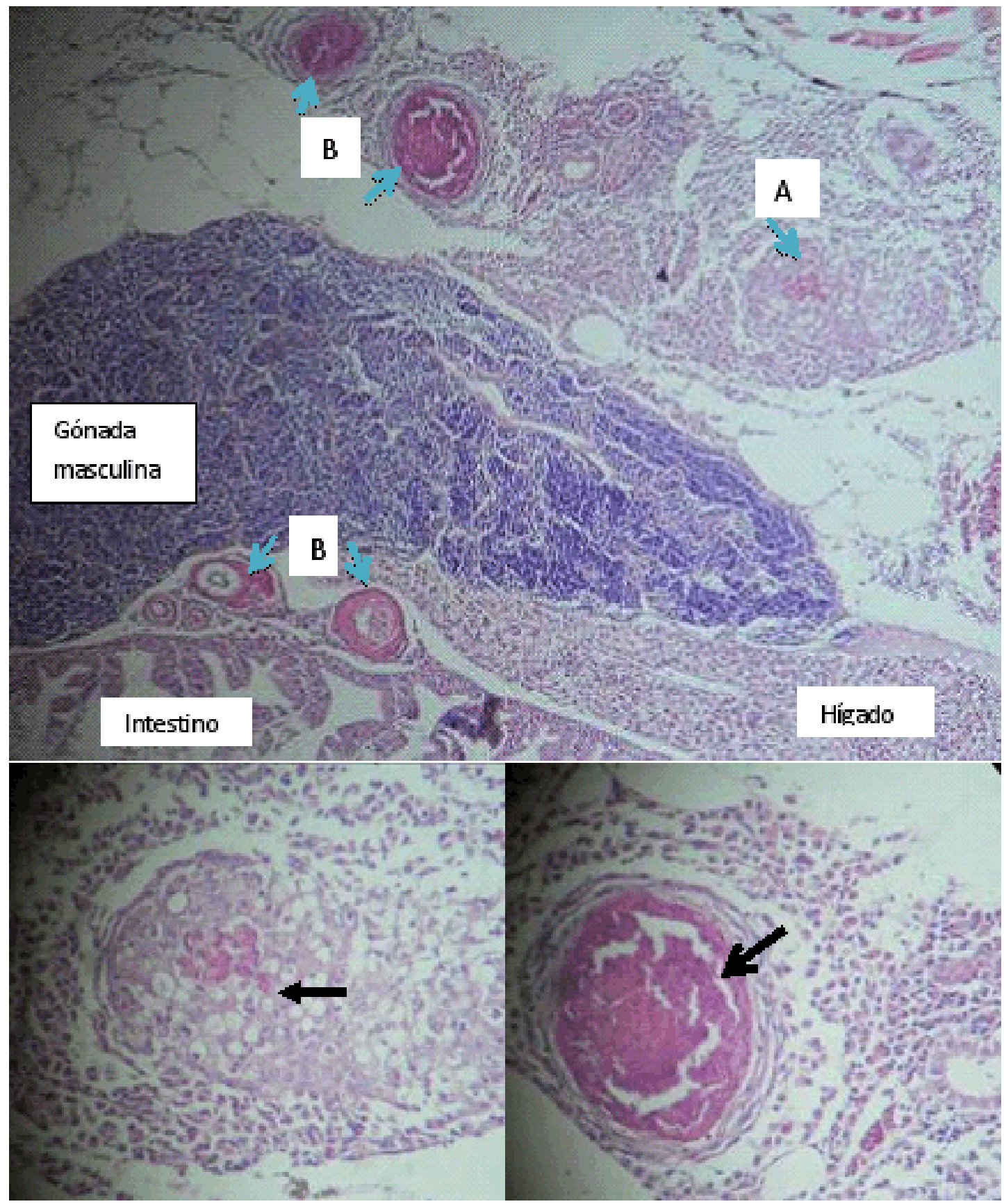

Figura 7. Granulomas bacterianos (flechas azules). H\&E. 1000X. A. Fase inicial con formación nodular, constituida por macrófagos con citoplasma espumoso, un ligero centro necrótico y una leve presencia de fibroblastos alrededor (flecha). H\&E. 1000X. B. Se observa un centro necrótico grande intensamente acidófilo, rodeados por varias capas laminares de fibroblastos (flecha). H\&E. 1000X 
La degeneración hidrópica encontrada en el riñón, según Hibiya et al. (1982), antecede a la presentación de la degeneración hialina, la cual, en exceso, podría conllevar a la necrosis del epitelio. Por otro lado, Ferguson (2006) menciona que la necrosis inducida por el hexaclorobutadieno (HCBD) en goldfish (Carassius auratus auratus), provoca degeneración hidrópica haciendo que se vea claramente la hinchazón celular en las tinciones con H\&E. No obstante, las lesiones renales encontradas en el presente estudio, podrían ser explicadas por causas relacionadas a una mala calidad del agua.

En el hígado solo se encontró una escasa degeneración hidrópica en el 11.9\% de los peces y una severa degeneración grasa en el $36.9 \%$ de los mismos, sin que hubiera manifestación de signos clínicos; mientras que López et al. (2001) reportaron 82\% de cambios degenerativos en el hígado de salmonídeos, donde la degeneración grasa y vacuolar fueron las más frecuentes. Tacon (1992) y Ferguson (2006) describen como una de las principales causas de degeneración hidrópica y grasa, los altos niveles de ácidos grasos poliinsaturados en las dietas, lo que lleva a cambios oxidativos en los lípidos (rancidez) si se almacenan en altas temperaturas y expuestas al oxígeno atmosférico, o en ausencia de un adecuado antioxidante como la vitamina $\mathrm{E}$.

Los cambios degenerativos en el hígado también pueden deberse a un exceso de lípidos y nutrientes energéticos en la dieta (Kalogeropoulos et al., 1992; Reyna, 1993; Wolf y Wolfe, 2005). Vigliano et al. (2002), por su lado, los relacionan con ayunos prolongados. Asimismo, la deficiencia de colina puede ocasionar degeneración grasa ya que es un factor lipotrópico, indispensable en el transporte de grasas, siendo necesaria en la dieta de los peces (Cowey y Roberts, 1981). Por otro lado, Wolf y Wolfe (2005) sostienen que debido a que una diversidad de peces tiene la capacidad de almacenar grandes cantidades de lípidos, se hace difícil distinguir las clases de vacuolas lipídicas que son conside- radas excesivas, por lo que no hay un adecuado criterio para el diagnóstico de lipidosis hepática.

La presencia de esporas y quistes parasitarios no ocasionaron una reacción inflamatoria en la periferia ni daños en el tejido. Ferguson (2006) sostiene que la mayoría de los microsporidios con estadios inmaduros parecen producir una leve o nula respuesta inflamatoria y, generalmente, son encontrados como hallazgos incidentales en el trabajo de rutina diagnóstica. La presencia de microsporidios podría deberse a las condiciones del medio ambiente, manejo, grado de infestación o inmunidad del hospedero (González y Heredia, 1998).

La necrosis muscular en el músculo esquelético en todos los peces que no presentaban quistes parasitarios, se manifestaron en forma leve y moderada. Este tipo de lesiones, aunque en forma más severa han sido descritas en el bagre de canal (Ictalurus punctatus) alimentados con dietas de niveles bajos de $\alpha$-tocoferol (Lovell et al., 1984) y con altos niveles de ácidos grasos poliinsaturados (Murai y Andrews, 1974); sin embargo, en el presente estudio se puede descartar esto último debido a la ausencia de necrosis del epitelio en el tubo digestivo.

\section{Conclusiones}

- La mayor frecuencia de lesiones en tejidos de peces tetra neón (Paracheirodon innesi) fueron por causas infecciosas de tipo parasitario, especialmente por Microsporidium.

- $\quad$ Estos peces puede ser afectados por más de un género de Microsporidium, identificándose por su morfología a Pleistophora sp y Heterosporis sp, por primera vez en el país.

- El músculo fue el tejido donde más agentes infecciosos fueron identificados.

- Se aislaron bacterias potencialmente patógenas tales como Flavobacterium sp, Staphylococcus sp, Carnobac- 
terium sp, Pseudomonas sp, Enterococcus sp, Bacillus sp y de la familia Enterobacteriaceae.

- A pesar de no haberse encontrado lesiones histopatológicas característicos de los agentes bacterianos aislados, se pudo observar múltiples granulomas, característicos en algunos procesos infecciosos de tipo bacteriano.

\section{Literatura Citada}

1. Auburn University. 2014. Alabama International Center for Aquaculture and Aquatic Environments. [Internet]. Disponible en: http:// www.auburn.edu/

2. Buller N. 2004. Bacteria from fish and other aquatic animals: A practical identification manual. London: CABI. 361 p. doi: 10.1079/9780851997384.0000

3. Centeno L, Silva-Acuña A, Silva-Acuña $R$, Pérez J. 2004. Fauna ectoparasitaria asociada a Colossoma macropomun y al hibrido de C. macropomum x Piaractus brachypomas, cultivados en el estado Delta Amacuro, Venezuela. Biagro 16: 121-126.

4. Cowey C, Roberts R. 1981. Patología de la nutrición de los teleósteos. En: Roberts R (eds). Patología de los peces. Madrid: Mundi-Prensa. p 249-261.

5. Farhadi A, Banan A, Fields J, Keshavarzian J. 2003. Intestinal barrier: an interface between health and disease. J Gastroenterol Hepatol 18: 479497. doi: 10.1046/j.1440-1746.2003.03032.x

6. Ferguson H. 2006. Systemic pathology of fish. A text and atlas of normal tissues in teleosts and their responses in disease. $2^{\text {nd }}$ ed. Iowa: Scotian Press. 366 p.

7. González J, Heredia B. 1998. Cultivo de la cachama (Colossoma macropomum). Fondo Nacional de Investigaciones Agropecuarias, Centro de Investigaciones Agropecuarias del Estado Guárico. Maracay, Venezuela. 134 p.
8. Herbert R, Dauner E. 2002. Enciclopedia de peces de acuario de agua dulce. España: Hispano Europea.1010 p.

9. Hibiya T, Yokote M, Oguri M, Sato H, Takashima F, Aida K. 1982. An atlas of fish histology. Normal and pathological features. Tokyo: Kodansha. 147 p.

10. Jubb K, Kennedy P, Palmer N. 2007. Pathology of domestic animals. $5^{\text {th }}$ ed. USA: Academic Press. 653 p.

11. Kalogeropoulus $N$, Alexis $M$, Henderson R. 1992. Effects of dietary soybean and cod-liver oil levels on growth and body composition of gilthead (Spaurus aurata). Aquaculture 104: 293-308. doi: 10.1016/00448486(92)90211-3

12. Kubitza F. 2009. Panorama da Aquicultura. [Internet]. Disponible em: http:/ /www.acquaimagem.com.br/docs/ Pan113_kubitza.pdf

13. Lambert G. 2003. Stress-induced gastrointestinal barrier dysfunction and its inflammatory effects. J Anim Sci 87(Suppl 14): E101-E108. doi: 10.2527/ jas.2008-1339

14. López I, Cubillos M, Ernst S, Rosenfeld C. 2001. Frecuencia y distribución, según edad y estacionalidad, de patologías hepáticas em salmonídeos, provenientes de la X a XII Región de Chile. Periodo 1988-1998. Arch Med Vet 33: 193-202. doi: 10.4067/S0301732X2001000200008

15. Lovell R, Miyazaki T, Rabegnator $S$. 1984. Requirement for alpha-tocopherol by channel catfish fed diets low in polyunsaturated triglycerides. J Nutr 114: 894-901.

16. Murai T, Andrews J. 1974. Interactions of dietary alpha-tocopherol, oxidized menhaden oil and ethoxyquin on channel catfish (Ictalurus punctatus). J Nutr 104: 1416-1431.

17. Noga J. 2000. Fish disease. Diagnosis and treatment. USA: Iowa State University Press. 497 p. 
18. Petracini R. 2013. El acuarista: acuariofilia y disciplinas afines. [Internet]. Disponible en: http:// www.elacuarista.com

19. Reimschuessel R, May E, Bennett R, Lypsky M. 1988. Tropical fish medicine. Necropsy examination of fish. Vet Clin NAm-Small 18: 427-433.

20. Reimschuessel R, Bennett R, Lypsky M. 1992. Communications: a classification system for histological lesions. J Aquatic Anim Hlth 4: 135-143. doi: 10.1577/1548-8667(1992)004<0135:$\mathrm{CACSFH}>2.3 . \mathrm{CO} ; 2$

21. Reyna S. 1993. Patología celular y tisular. En: Trigo F, Poumián A (eds). Patología general veterinaria. México: Interamericana. p 26-30.

22. Roberts J, Shepherd J. 1980. Enfermedades de la trucha y el salmón. España: Acribia. $187 \mathrm{p}$.

23. Roberts $R$. 2001. Fish pathology. $3^{\text {th }}$ ed. London: WB Saunders. 412 p.

24. Rojas J. 1972. Establecimiento de cooperativas en peces ornamentales en Iquitos. Tesis de Biólogo. Iquitos: UNAP. $70 \mathrm{p}$.

25. Ross L, Ross B. 2008. Anaesthetic and sedative techniques for aquatic animals. $3^{\text {th }}$ ed. Singapore: Wiley-Blackwell. 240 p.
26. Rosenthal S. 2007. Frecuencia de lipidosis hepática en truchas arcoíris (Oncorhynchus mykiss) de fase juvenil en una piscigranja de la sierra central del Perú. Tesis de Médico Veterinario. Lima: Univ Nacional Mayor de San Marcos. 69 p.

27. Ruíz A, Souza J, Vela U. 2003. Análisis situacional de la pesquería ornamental en Iquitos y áreas de influencia - base para una propuesta de manejo. Tesis de Maestría. Iquitos: UNAP. 176 p.

28. Tacon A. 1992. Nutritional fish pathology morphological signs of nutrient deficiency and toxicity in farmed fish. FAO Fisheries Technical Paper. Rome: FAO. 75 p.

29. Verján N. 2002. Sistematización diagnóstica y caracterización de las enfermedades de la cachama blanca (Piaractus brachypomus) en algunas regiones de los Llanos Orientales de Colombia y estudio de la enfermedad septicémica. Tesis de Maestría. Bogotá: Univ Nacional de Colombia. 120 p.

30. Vigliano F, Quiroga M, Nieto J. 2002. Adaptaciones metabólicas al ayuno y realimentación en peces. Rev Ictiol 10 (1/2): 79-108.

31. Wolf J, Wolfe M. 2005. A brief overview of nonneoplastic hepatic toxicity in fish. Toxicol Pathol 33: 75-85. 